\title{
Noninvasive visualization of acute myocardial infarction in man with Thallium-20I
}

\author{
Frans J. Th. Wackers, Jan B.v.d. Schoot, Ellinor Busemann Sokole, Gerard Samson, \\ Gerrit J. C. v. Niftrik, K. I. Lie, Dirk Durrer, and Hein J. J. Wellens \\ From the Departments of Cardiology and Nuclear Medicine, University of Amsterdam, Wilhelmina Gasthuis, \\ Amsterdam, The Netherlands
}

\begin{abstract}
Myocardial imaging using ${ }^{201} \mathrm{Tl}$ was performed in Io patients with supposedly normal myocardial perfusion and in II patients with acute myocardial infarction. In all patients with acute myocardial infarction the scintiscan showed an area with diminished radioactivity at the site corresponding to electrocardiographic localization of the infarction. ${ }^{201} \mathrm{Tl}$ seems to be of diagnostic value for recognizing acute myocardial infarction in the very first hours after its onset and for visualizing infarction in patients in whom pre-existing electrocardiographic abnormalities prevent its diagnosis and/or localization.
\end{abstract}

Myocardial imaging with intravenously administered radioisotopes of rubidium, caesium, and potassium has been studied since 1962 (Carr et al., 1962, 1964). ${ }^{43} \mathrm{~K}$ has been most widely used (Zaret $e t$ al., 1973, 1974) but is not ideal because of its high photon energies, its short shelf-life ( $t_{1}$ (phys.) $=23.4 \mathrm{hr}$ ), and its high cost. Lebowitz has recently reported that ${ }^{201} \mathrm{Tl}$ accumulates in the myocardium of goats (Lebowitz et al., 1973). Since the energies of the photons emitted by ${ }^{201} \mathrm{Tl}$ are relatively low and since this radionuclide has a physical half-life of 73.5 hours, it should be more useful than ${ }^{43} \mathrm{~K}$ for scintigraphy of the myocardium. This paper presents the results of preliminary investigations using ${ }^{201} \mathrm{Tl}$ for the visualization of the normal myocardium and of acute myocardial infarction in man.

\section{Subjects and methods}

${ }^{201} \mathrm{Tl}$ as thallium (I) chloride in saline solution, with a specific activity of more than $500 \mathrm{mCi}$ per $\mathrm{mg}$ thallium, was used as the radiopharmaceutical. The thallium concentration was less than Io $\mu \mathrm{mol} / 1 .^{1}$ Images were obtained with a gamma camera (Nuclear Chicago HP III) using the high resolution 16000 parallel holes collimator; the data were converted to digital form via a 4096 multichannel analyser and stored on magnetic tape for replay and analysis. The energy window of the gamma camera was set over the $69-82 \mathrm{keV}$ range be-

Received 16 December 1974.

${ }^{1}$ Thallium-20I was supplied by Dr. R. B. J. de Jong, N. V. Philips-Duphar, Cyclotron and Isotope Laboratories, Petten, Holland. cause of the predominance of this energy in the decay spectrum of ${ }^{201} \mathrm{Tl}$. The high energy photons produced minimal influence on the scintigraphic images when using the 16000 holes collimator.

After initial studies in dogs, scintigraphy of the myocardium was performed in 21 patients. Ten had no clinical and electrocardiographic signs of coronary artery disease and were assumed to have normal myocardial perfusion (Table I). Eleven patients had acute myocardial infarction, the diagnosis based upon a typical history of chest pain and serial changes in serum enzyme levels (aspartate aminotransferase, lactic dehydrogenase, creatine phosphokinase). Apart from one patient who had left bundle-branch block on admission, all patients showed the appearance of diagnostic $Q$ waves and ST- $T$ segment changes (Table 2). Informed consent was obtained from all patients before performance of the ${ }^{201} \mathrm{Tl}$ study.

TABLE I Patients with supposedly normal myocardial perfusion

\begin{tabular}{|c|c|c|c|}
\hline $\begin{array}{l}\text { Case } \\
\text { No. }\end{array}$ & $\begin{array}{l}\text { Age } \\
(y r)\end{array}$ & Sex & Clinical diagnosis \\
\hline $\mathbf{I}$ & 62 & \multirow{9}{*}{$\begin{array}{l}M \\
F \\
M \\
M \\
M \\
M \\
F \\
M \\
F \\
M\end{array}$} & \multirow{9}{*}{$\begin{array}{l}\text { Bronchial asthma } \\
\text { Emphysema } \\
\text { Venous thrombosis } \\
\text { Hypercalcaemia } \\
\text { Venous thrombosis } \\
\text { Vasovagal collapse } \\
\text { Bronchial asthma } \\
\text { Bronchial carcinoma } \\
\text { Pulmonary embolism } \\
\text { Vasovagal collapse }\end{array}$} \\
\hline 2 & 52 & & \\
\hline 3 & 61 & & \\
\hline 4 & 57 & & \\
\hline $\begin{array}{l}5 \\
6\end{array}$ & $\begin{array}{l}54 \\
84\end{array}$ & & \\
\hline 7 & 52 & & \\
\hline 8 & 72 & & \\
\hline 9 & 75 & & \\
\hline 10 & 58 & & \\
\hline
\end{tabular}


TABLE 2 Patients with acute myocardial infarction

\begin{tabular}{|c|c|c|c|c|c|}
\hline $\begin{array}{l}\text { Case } \\
\text { No. }\end{array}$ & $\begin{array}{l}\text { Age } \\
(y r)\end{array}$ & Sex & \multicolumn{2}{|c|}{$\begin{array}{l}\text { Localization } \\
\text { ECG Scan }\end{array}$} & $\begin{array}{l}\text { Days after } \\
\text { onset myo- } \\
\text { cardial } \\
\text { infarction }\end{array}$ \\
\hline I & $5^{8}$ & $\mathbf{M}$ & \multirow{11}{*}{$\begin{array}{l}\text { AS } \\
\text { I+P } \\
\text { LBBB } \\
\text { AS + L } \\
\text { AL } \\
\text { AS + L } \\
\text { I } \\
\text { P+L } \\
\text { AS } \\
\text { A } \\
\text { AL }\end{array}$} & \multirow{11}{*}{$\begin{array}{l}\text { AS } \\
\text { P } \\
\text { AL } \\
\text { AS + L } \\
\text { AL } \\
\text { AL } \\
\text { I+P } \\
\text { P+I } \\
\text { AS+L } \\
\text { Apic } \\
\text { AL }\end{array}$} & 12 \\
\hline 2 & 60 & $\mathbf{M}$ & & & 5 \\
\hline 3 & 70 & $\mathbf{M}$ & & & 6 \\
\hline 4 & 72 & $\mathbf{M}$ & & & 6 \\
\hline 5 & 72 & $\mathbf{M}$ & & & 7 \\
\hline 6 & 62 & $\mathbf{M}$ & & & 5 \\
\hline 7 & 72 & $\mathbf{M}$ & & & 5 \\
\hline 8 & 71 & $\mathbf{M}$ & & & 2 \\
\hline 9 & 53 & $\mathbf{M}$ & & & 5 \\
\hline ro & 65 & $\mathbf{M}$ & & & 5 \\
\hline II & 68 & $\mathbf{M}$ & & & I0 \\
\hline
\end{tabular}

Abbreviations: AS: anteroseptal; I: inferior; $\mathrm{P}$ : posterior; LBBB; left bundle-branch block; A: anterior; L: lateral; Apic: apical.

With the patient in a supine position, frontal images were obtained using the following procedure.

I) A transmission scintiscan was made with a collimated flat source of ${ }^{99 \mathrm{~m}} \mathrm{Tc}$ in order to position the patient's heart in the image field and to determine cardiac contours,

2) $2 \mathrm{mCi}{ }^{201} \mathrm{Tl}$ in less than $4 \mathrm{ml}$ saline was rapidly injected intravenously,

3) Immediately after injection, serial scintiscans were made to localize the ventricular cavities,

4) Five-minute scintiscans were made consecutively up to 25 minutes after injection, each scintiscan accumulating approximately $150 \mathrm{k}$ counts.

Finally a left lateral scintiscan was made with the patient lying on his right side.

In order to study the distribution of ${ }^{201} \mathrm{Tl}$ in the body, whole body scans were made of two patients three times during 6 days after injection, with a dual head $12.7 \mathrm{~cm}$ crystal rectilinear scanner (Elscint), measuring the 69 to $82 \mathrm{keV}$ radiation. In 4 patients the ${ }^{201} \mathrm{Tl}$ radio-activity in urine and faeces was measured during 6 days after the intravenous injection.

\section{Results}

All the cardiac images of the ro patients with supposedly normal myocardial perfusion displayed a horseshoe or ovoid pattern (Fig. I). The right ventricular mass was not visualized. All frontal and lateral scans of patients with acute myocardial infarction showed an area of decreased radioactivity (Fig. 2 and 3), corresponding to the electrocardiographic localization of the infarction (Table 2). Optimal scintiscans were obtained approximately 20 minutes after ${ }^{201} \mathrm{Tl}$ injection.

${ }^{201} \mathrm{Tl}$ accumulates in all organs of the body. Increased uptake is seen in myocardium ( 2 to $3 \%$ in

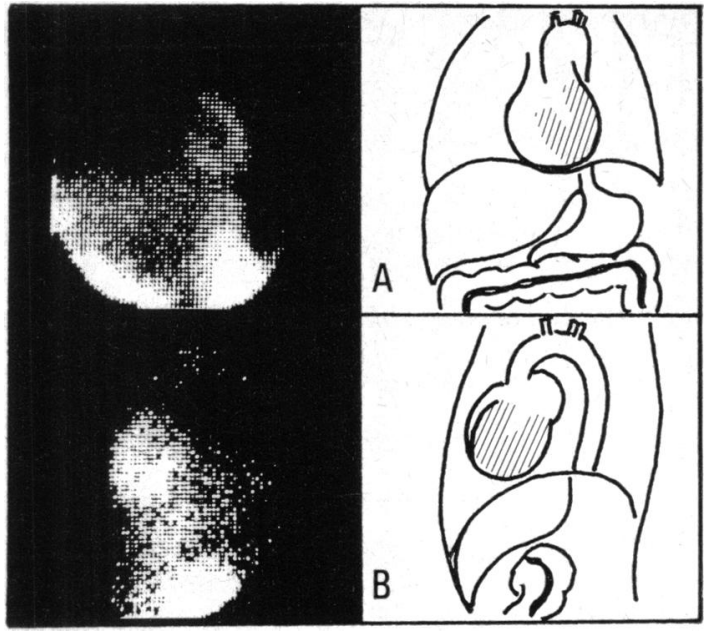

FIG. I Normal myocardium. The cardiac image displays a horseshoe pattern both on frontal $(A)$ and left lateral $(B)$ image. Scintiscans are shown on the left side and schematic drawings are shown on the right side.

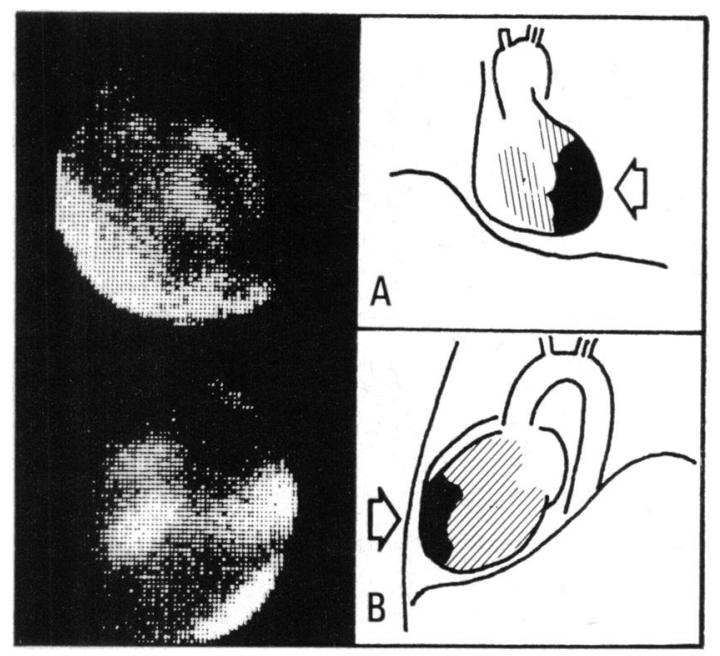

FIG. 2 Anterolateral infarction. The frontal $(A)$ and left lateral $(B)$ scintiscans show an area of diminished activity (arrows) at the site of infarction.

the first hour), liver, and kidneys, and in variable amounts in the digestive tract, e.g. stomach and colon. Preliminary measurements suggest that approximately 12 per cent of the administered activity is excreted with the urine and 6 per cent with the faeces. 


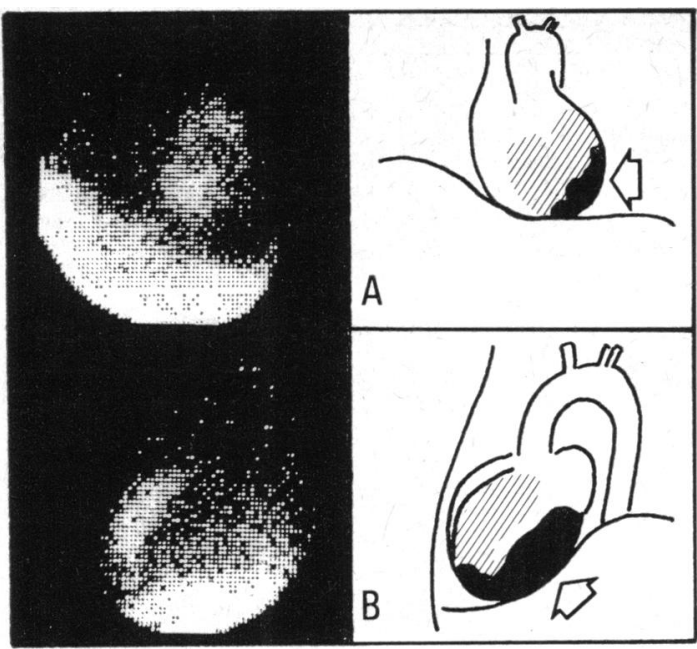

FIG. 3 Posterolateral infarction. Frontal $(A)$ and left lateral $(B)$ scintiscans. The arrows indicate an area of diminished activity corresponding to the site of infarction.

\section{Discussion}

${ }^{201} \mathrm{Tl}$ accumulates in the myocardium. The mass of the right ventricle is probably too small to provide an image. Infarcted myocardium produces a region of reduced radioactivity. Localization of the infarction was possible by combining scintiscans from two directions. Inferior and posterior wall infarctions were clearly discernible on the left lateral scintiscans (Fig. 3).

The amount of thallium that is administered to the patients has always been less than $0.04 \mu \mathrm{mol}$. The LD50 dose is generally accepted to be a factor of $10^{4}$ more.

On the basis of experiments in rodents, van Putten has estimated the radiation dose to the kidneys in man to be $3.8 \mathrm{rad}(\mathrm{cJ} / \mathrm{kg})$ per $\mathrm{mCi}$ (L. M. van Putten, 1974, personal communication). We are performing measurements on radiation doses from ${ }^{201} \mathrm{Tl}$ in man and dogs, and studies on the early detection of acute myocardial infarction in dogs. In a preliminary study, when ${ }^{201} \mathrm{Tl}$ was injected intravenously in two dogs 30 minutes after ligation of one of the branches of the left anterior descending artery, an area of reduced activity was found on the scintiscan of the myocardium 20 minutes after injection.

The early diagnosis of myocardial infarction is of obvious clinical importance. Visualization of acute myocardial infarction using the method described is especially useful in patients with a suggestive clinical history but where the electrocardio- gram is not helpful, for example because of the presence of an old infarction, or an abnormal cardiac activation process, such as in pre-excitation, left bundle-branch block, or during a pacemaker rhythm. For these patients, where, in the absence of liver disease it usually takes one day to establish myocardial necrosis with routine enzyme studies, ${ }^{201} \mathrm{Tl}$ scintigraphy of the myocardium will be of the greatest importance for localization and identification of the infarction.

Other possible applications of this noninvasive method could be the estimation of the size of infarction, post coronary bypass evaluation, and the study of the natural history in the infarcted area by sequential scintiscans.

Recently Holman et al. reported on visualizing acute myocardial infarction as an area of increased radioactivity using ${ }^{99 \mathrm{~m}} \mathrm{Tc}(\mathrm{Sn})$ tetracycline (Holman et al., 1974). Optical imaging, however, was not achieved until 24 hours after injection. A more appropriate radiopharmaceutical, which could be used in combination with ${ }^{201} \mathrm{Tl}$, is probably ${ }^{99 \mathrm{~m}} \mathrm{Tc}$ (Sn) pyrophosphate. The latter complex gives an area of increased radioactivity in the infarcted myocardium half an hour after injection, but not earlier than one day after onset of acute myocardial infarction (Parkey et al., 1974). Kramer et al. (1974) found that ${ }^{67} \mathrm{Ga}$ accumulates in the infarcted myocardium of animals. This radionuclide, which is labelled to leucocytes in vivo, does not produce an image in the early phase of myocardial infarction.

Scintigraphy with ${ }^{201} \mathrm{Tl}$ seems to be of great clinical importance as a noninvasive and simple technique for visualizing acute myocardial infarction. Results in dogs suggest that by this method myocardial infarction can be recognized already in the first hours after its onset. The advantages of ${ }^{201} \mathrm{Tl}$ over other radionuclides presently used for myocardial imaging are the relative ease of production, the low energy electromagnetic radiation, the relatively long shelf-life, and the short time interval both between the injection and the optimal scintiscan and between the onset of infarction and the scintigraphic results.

\section{References}

Carr, E. A., Beierwaltes, W. H., Wegst, A. V., and Bartlett, J. D. (1962). Myocardial scanning with rubidium-86. fournal of Nuclear Medicine, 3, 76.

Carr, E. A., Gleason, G., Shaw, J., and Krontz, B. (1964). The direct diagnosis of myocardial infarction by photoscanning after administration of cesium-r3r. American Heart fournal, 68, 627.

Holman, B. L., Lesch, M., Zweiman, F. G., Temte, J., Lown, B., and Gorlin, R. (1974). Detection and sizing of acute myocardial infarcts with ${ }^{80 \mathrm{~m} T c}(\mathrm{Sn})$ tetracycline. New England fournal of Medicine, 291, 159. 
Kramer, R. J., Goldstein, R. E., Hirschfeld, J. W., Roberts, W. C., Johnston, G. S., and Epstein, S. E. (1974). Accumulation of Gallium-67 in regions of acute myocardial infarction. American fournal of Cardiology, 33, 861.

Lebowitz, F., Greene, M. W., Bradley-Moore, P., Atkins, H., Ansari, A., Richards, P., and Belgrave, E. (1973). Thallium-20I for medical use. Paper presented at the 20th Annual Meeting of the Society of Nuclear Medicine, Miami Beach, Florida, 12-15 June, abstracted in fournal of Nuclear Medicine, 14, $42 \mathrm{r}$.

Parkey, R. W., Bonte, F. J., Meyer, S. L., Atkins, J. M., Curry, G. L., Stokely, E. M., and Willerson, J. T. (1974). A new method for radionuclide imaging of acute myocardial infarctions in humans. Circulation, 50, 540.
Zaret, B. L., Martin, N. D., McGowan, R. L., Strauss, H. W., Wells, H.P., and Flamm, M. D. (I974). Rest and exercise Potassium-43 myocardial perfusion imaging for the noninvasive evaluation of aorta-coronary bypass surgery. Circulation, 49, 688.

Zaret, B. L., Strauss, H. W., Martin, N. D., Wells, H. P., and Flamm, M. D. (1973). Noninvasive regional myocardial perfusion with radioactive potassium. Nerv England fournal of Medicine, 288, 809.

Request for reprints to Frans J. Th. Wackers, M. D., University of Amsterdam, Department of Cardiology, Wilhelmina Gasthuis, Amsterdam, The Netherlands.

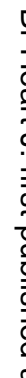

